\title{
Small Intestine Infection, CTCAE
}

National Cancer Institute

\section{Source}

National Cancer Institute. Small Intestine Infection, CT CAE. NCI Thesaurus. Code C143845.

A disorder characterized by an infectious process involving the small intestine. 